\title{
Benign Kidney Hemangiopericytoma
}

National Cancer Institute

\section{Source}

National Cancer Institute. Benign Kidney Hemangiopericytoma. NCI Thesaurus. Code C6950.

A benign hemangiopericytoma arising from the kidney. 